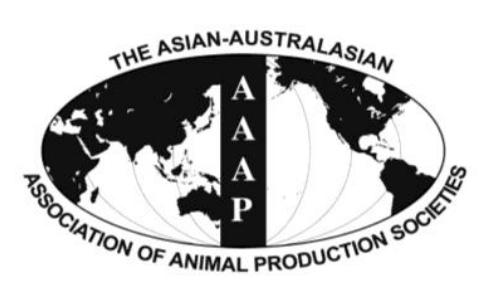

Open Access

Asian Australas. J. Anim. Sci.

Vol. 27, No. 12 : 1744-1748 December 2014

http://dx.doi.org/10.5713/ajas.2014.14252

www.ajas.info

pISSN 1011-2367 elSSN 1976-5517

\title{
Effects of Pyridoxine on Growth Performance and Plasma Aminotransferases and Homocysteine of White Pekin Ducks
}

\author{
Ming Xie, Jing Tang, Zhiguo Wen, Wei Huang, and Shuisheng Hou* \\ Institute of Animal Sciences, Chinese Academy of Agricultural Sciences, Beijing 100193, China
}

\begin{abstract}
A dose-response experiment with seven supplemental pyridoxine levels $(0,0.66,1.32,1.98,2.64,3.30, \mathrm{and} 3.96 \mathrm{mg} / \mathrm{kg})$ was conducted to investigate the effects of pyridoxine on growth performance and plasma aminotransferases and homocysteine of White Pekin ducks and to estimate pyridoxine requirement for these birds. A total of 336 one-day-old male White Pekin ducks were divided to 7 experimental treatments and each treatment contained 8 replicate pens with 6 birds per pen. Ducks were reared in raised wire-floor pens from hatch to $28 \mathrm{~d}$ of age. At $28 \mathrm{~d}$ of age, the weight gain, feed intake, feed/gain, and the aspartate aminotransferase, alanine aminotransferase, and homocysteine in plasma of ducks from each pen were all measured. In our study, the pyridoxine deficiency of ducks was characterized by growth depression, decreasing plasma aspartate aminotransferase activity and increasing plasma homocysteine. The ducks fed vitamin $\mathrm{B}_{6}$-deficient basal diets had the worst weight gain and feed/gain among all birds and this growth depression was alleviated $(\mathrm{p}<0.05)$ when pyridoxine was supplemented to basal diets. On the other hand, plasma aspartate aminotransferase and homocysteine may be the sensitive indicators for vitamin $\mathrm{B}_{6}$ status of ducks. The ducks fed basal diets had much lower aspartate aminotransferase activity and higher homocysteine level in plasma compared with other birds fed pyridoxinesupplemented diets $(\mathrm{p}<0.05)$. According to quadratic regression, the supplemental pyridoxine requirements of Pekin ducks from hatch to 28 days of age was $2.44 \mathrm{mg} / \mathrm{kg}$ for feed/gain and $2.08 \mathrm{mg} / \mathrm{kg}$ for plasma aspartate aminotransferase and the corresponding total requirements of this vitamin for these two criteria were 4.37 and $4.01 \mathrm{mg} / \mathrm{kg}$ when the pyridoxine concentration of basal diets was included, respectively. All data suggested that pyridoxine deficiency could cause growth retardation in ducks and the deficiency of this vitamin could be indicated by decreasing plasma aspartate aminotransferase activity and increasing plasma homocysteine. (Key Words: Duck, Pyridoxine, Vitamin, Aminotransferase, Homocysteine)
\end{abstract}

\section{INTRODUCTION}

Pyridoxine (vitamin $\mathrm{B}_{6}$ ) and its hydrochlorate salt is usually supplemented to poultry diets as the source of this vitamin. In the early years, the pyridoxine deficiency in ducks was observed by Hegsted and Rao (1945) and the pyridoxine recommendation of NRC (1994) for White Pekin ducks was $2.5 \mathrm{mg} / \mathrm{kg}$. However, since the publication of NRC (1994), further information on duck vitamin $B_{6}$ requirements was not reported and it is still little for other avian species. Furthermore, due to improved growth rate and the change in feeding conditions of meat poultry

\footnotetext{
* Corresponding Author: Shuisheng Hou. Tel: +86-10-6281-6227, Fax: +86-10-6281-5832, E-mail: houss@263.net

Submitted Apr. 5, 2014; Revised Jun. 5, 2014; Accepted Jul. 8, 2014
}

compared with the past decades, it is time to reevaluate the requirement of this vitamin.

Pyridoxine can be converted to pyridoxal-5'-phosphate (PLP) and then takes part in the transamination pathway for amino acids as a coenzyme. In chicks, transaminases are sensitive and specific indicators for vitamin $B_{6}$ status and vitamin $\mathrm{B}_{6}$ deficiency significantly reduces the activities of aspartate aminotransferase and alanine aminotransferase in blood (Cheney et al., 1965; Yen et al., 1976; Oloyo, 2001), but its indicator status has not been reported in ducks. On the other hand, because plasma homocysteine was thought to be a risk factor for cardiovascular disease, vitamin $\mathrm{B}_{6}$ is widely recognized for its importance in the inactivation of homocysteine by serving as coenzyme in the form of PLP for two degradative enzymes (cystathionine $\beta$-synthase and cystathionine $\gamma$-lyase) in the transsulfuration pathway for 
homocysteine removal (Selhub, 1999; Miles and Kraus, 2004). In vitamin $B_{6}$-deficient rats and pigs, plasma homocysteine was significantly elevated (Smolin et al., 1983; Martinez et al., 2000; Lima et al., 2006; Zhang et al., 2009) which indicated that vitamin $B_{6}$ deficiency may have potential negative effects on vascular health of animals. Therefore, plasma homocysteine may be another new and useful biomarker for vitamin $\mathrm{B}_{6}$ status of animals. However, the effects of vitamin $B_{6}$ on homocysteine status of ducks and other avian species have not been confirmed.

Herein, considering that the information on vitamin $\mathrm{B}_{6}$ nutrition of modern duck strains is lacking, the objective of present study was to examine the effects of pyridoxine on growth performance and plasma aminotransferases and homocysteine of White Pekin ducks and to determine the pyridoxine requirements for modern duck strains.

\section{MATERIALS AND METHODS}

All procedures in our experiments were approved by the animal care and use committee of the Institute of Animal Sciences of Chinese Academy of Agricultural Sciences. A dose-response experiment with seven supplemental pyridoxine levels $(0,0.66,1.32,1.98,2.64,3.30$, and 3.96 $\mathrm{mg} / \mathrm{kg}$ ) was utilized. The basal diet was formulated to be vitamin $\mathrm{B}_{6}$ deficient (Table 1) and it contained $1.93 \mathrm{mg} / \mathrm{kg}$ total pyridoxine by calculation according to the data of feed ingredients of the NRC (1994). To produce experimental diets, the basal diet was produced first and then seven experimental diets were constructed by blending the basal diet with different supplemental levels of crystal pyridoxine $\cdot \mathrm{HCl}$ containing $82 \%$ free base. The supplemental pyridoxine levels of experimental diets were analyzed by high performance liquid chromatography (2695 Alliance, Waters, Milford, MA, USA) with fluorescence detection after extraction by hot water according to the method recommended by the Ministry of Health of China (2010). The analyzed supplemental pyridoxine concentrations in the seven experimental diets were $0,0.69$, $1.33,1.96,2.67,3.35$, and $3.99 \mathrm{mg} / \mathrm{kg}$, respectively, which were similar to the calculated pyridoxine values. A total of 336 one-day-old male White Pekin ducks with average body weight of $57 \pm 3 \mathrm{~g}$ were divided to 7 experimental treatments and each treatment contained 8 replicate pens with 6 birds per pens. These ducklings were reared in raised wire-floor pens $(200 \times 100 \times 40 \mathrm{~cm})$ from hatch to 28 days of age. During this period, the birds were given free access to water and feed. Water was provided by drip-nipple and feed was fed in pellet form. In the birdhouse, lighting was continuous and the temperature was kept at $33^{\circ} \mathrm{C}$ from 1 to 3 days of age and then it was reduced gradually to room temperature until 21 days of age.

At twenty-eight days of age, the weight gain, feed
Table 1. Composition of basal diet ( $\%$ as fed)

\begin{tabular}{|c|c|}
\hline Items & Content $(\%)$ \\
\hline \multicolumn{2}{|l|}{ Ingredients } \\
\hline Wheat & 25.0 \\
\hline Corn starch & 50.62 \\
\hline Isolated soybean protein & 20.00 \\
\hline $\mathrm{NaCl}$ & 0.30 \\
\hline Dicalcium phosphate & 2.0 \\
\hline Limestone & 0.8 \\
\hline $\operatorname{Premix}^{1}$ & 1.0 \\
\hline DL-methionine & 0.28 \\
\hline \multicolumn{2}{|l|}{ Calculated composition } \\
\hline Metabolizable energy $(\mathrm{kcal} / \mathrm{kg})^{2}$ & 3.07 \\
\hline Crude protein & 20.0 \\
\hline Pyridoxine (mg/kg) & 1.93 \\
\hline Calcium & 0.83 \\
\hline Nonphytate phosphorus & 0.41 \\
\hline Methionine & 0.50 \\
\hline Methionine+cystine & 0.77 \\
\hline Lysine & 1.17 \\
\hline Trptophan & 0.24 \\
\hline Arginine & 1.44 \\
\hline Ileucine & 0.84 \\
\hline Threonine & 0.77 \\
\hline Valine & 0.99 \\
\hline
\end{tabular}

Supplied per kilogram of total diet: $\mathrm{Cu}\left(\mathrm{CuSO}_{4} \cdot 5 \mathrm{H}_{2} \mathrm{O}\right), 8 \mathrm{mg} ; \mathrm{Fe}$ $\left(\mathrm{FeSO}_{4} \cdot 7 \mathrm{H}_{2} \mathrm{O}\right), 60 \mathrm{mg} ; \mathrm{Zn}(\mathrm{ZnO}), 60 \mathrm{mg} ; \mathrm{Mn}\left(\mathrm{MnSO}_{4} \cdot \mathrm{H}_{2} \mathrm{O}\right), 100 \mathrm{mg} ; \mathrm{Se}$ $\left(\mathrm{NaSeO}_{3}\right), 0.3 \mathrm{mg}$; I (KI), $0.4 \mathrm{mg} ; \mathrm{Mg}(\mathrm{MgO}), 200 \mathrm{mg} ; \mathrm{K}\left(\mathrm{K}_{2} \mathrm{CO}_{3}\right), 1,500$; choline chloride, $1,000 \mathrm{mg}$; vitamin A (retinyl acetate), 4,000 IU; vitamin $\mathrm{D}_{3}$ (Cholcalciferol), 2,000 IU; vitamin E (DL- $\alpha$-tocopheryl acetate), 20 IU; vitamin $\mathrm{K}_{3}$ (menadione sodium bisulfate), $2 \mathrm{mg}$; thiamin (thiamin mononitrate), $2 \mathrm{mg}$; riboflavin, $10 \mathrm{mg}$; cobalamin, $0.02 \mathrm{mg}$; calcium-Dpantothenate, $20 \mathrm{mg}$; nicotinic acid, $50 \mathrm{mg}$; folic acid, $1 \mathrm{mg}$; and biotin, $0.20 \mathrm{mg}$

${ }^{2}$ The value was calculated according to the apparent metabolizable energy of chickens.

intake, and feed/gain of all ducks from each pen were determined and 2 birds selected randomly from each pen were bled by heart puncture. Blood samples were collected into heparin sodium-anticoagulant tubes and centrifuged at 3,000 rpm for $10 \mathrm{~min}$ to obtain plasma. Plasma was kept at $-20^{\circ} \mathrm{C}$ until analyzed. Plasma homocysteine was determined using reversed-phase high performance liquid chromatography (2695 Alliance, Waters, Milford, MA, USA) with precolumn derivation and fluorescence detection according to the method of Ubbink et al. (1991) as modified by Gilfix et al. (1997) and Pfeiffer et al. (1999). The modification used tris (2-carboxylethyl)-phosphine as a reductant and 7-fluorobenzo-2-oxa-1,3-diazole-4-sulfonate as a fluorescent derivative reagent. Plasma enzyme activities of alanine aminotransferase and aspartate aminotransferase were determined using commercial kits (Zhongsheng Bio-Technology and Science Inc., Beijing, China) on a random access analyzer (Technicon RA 1000, Tarrytown, NY, USA). 
Data were analyzed as a completely randomized design by one-way analysis of variance procedure of SAS software (SAS Institute, 2003) with pen used as experimental unit for analysis and the linear and quadratic effects of pyridoxine were also tested by REG procedure of SAS software (SAS Institute, 2003). In our study, the quadratic regression was also used to estimate the supplemental pyridoxine requirement and the requirement was defined as $95 \%$ of supplemental pyridoxine level at maximum response.

\section{RESULTS AND DISCUSSION}

In our study, the vitamin $\mathrm{B}_{6}$ of basal diets mainly came from wheat and isolated soybean protein (Table 1) and the calculated pyridoxine in basal diets was $1.93 \mathrm{mg} / \mathrm{kg}$. However, the availability of pyridoxine in the basal diets may have been poor and their contribution to meet pyridoxine adequacy may be very limited because the major form of vitamin $B_{6}$ in plant-source feedstuffs was pyridoxine glucoside and this compounds has poor vitamin $\mathrm{B}_{6}$ bioactivity (Reynolds, 1988; Trumbo et al., 1988). At present, the information on the bioavailability of vitamin $B_{6}$ in plant-source feedstuffs is limited. In chicks, vitamin $\mathrm{B}_{6}$ in corn and soybean meal has about $40 \%$ and $60 \%$ bioavailability relative to crystal pyridoxine hydrochlorate salt, respectively (Yen et al., 1976), but the bioavailabilities of vitamin $B_{6}$ in wheat and isolated soybean protein is unknown in either chicks or ducks. Usually, crystal pyridoxine hydrochlorate salt is assumed to have 100\% vitamin $\mathrm{B}_{6}$ activity. Therefore, the duck response to increasing supplemental pyridoxine and the supplemental pyridoxine requirements for ducks are discussed.

In present study, the ducks fed basal diets with no supplementation of pyridoxine had the worst growth performance among all ducks but the weight gain and feed/gain of ducks were improved $(\mathrm{p}=0.0027$ or $\mathrm{p}=$ 0.0277 ) by increasing supplemental pyridoxine levels (Table 2). This indicated that the basal diet was clearly deficient in vitamin $B_{6}$ and that the experimental period was adequate to assess the duck response to increasing supplemental pyridoxine. However, only growth depression was observed in vitamin $\mathrm{B}_{6}$-deficient ducks in our study and this was not in agreement with the results of Hegsted and Rao (1945). In their study, severe acute pyridoxine deficiency in young ducklings was also characterized by severe anemia while chronic pyridoxine deficiency in older ducklings produced paralysis, convulsions, severe microcytic anemia, and poor feather development. Unfortunately, anemia was not investigated in our study but the paralysis, convulsions, and poor feather development were not observed in the ducks deficient in this vitamin in present study.

At present, transaminases serve as sensitive indicator for
Table 2. Effects of pyridoxine on growth performance of White Pekin ducks from hatch to 28 days of age ${ }^{1}$

\begin{tabular}{lccc}
\hline Items & $\begin{array}{c}\text { Daily } \\
\text { weight gain } \\
(\mathrm{g} / \mathrm{bird} / \mathrm{d})\end{array}$ & $\begin{array}{c}\text { Daily } \\
\text { feed intake } \\
(\mathrm{g} / \mathrm{bird} / \mathrm{d})\end{array}$ & $\begin{array}{c}\text { Feed/gain } \\
(\mathrm{g} / \mathrm{g})\end{array}$ \\
\hline Supplemental pyridoxine $(\mathrm{mg} / \mathrm{kg})$ & & \\
0.00 & 22.3 & 56.7 & 2.56 \\
0.66 & 28.8 & 66.7 & 2.41 \\
1.32 & 34.1 & 70.0 & 2.09 \\
1.98 & 28.0 & 58.4 & 2.11 \\
2.64 & 37.2 & 76.5 & 2.08 \\
3.30 & 33.2 & 71.6 & 2.16 \\
3.96 & 30.6 & 64.5 & 2.12 \\
Pooled SEM & 1.06 & 2.11 & 0.048 \\
Probability & & & \\
Pyridoxine & 0.0027 & 0.1285 & 0.0277 \\
Pyridoxine linear & 0.1679 & 0.3350 & 0.0533 \\
Pyridoxine quadratic & 0.1162 & 0.4074 & 0.0114 \\
\hline
\end{tabular}

SEM, standard error of the mean.

${ }^{1}$ Results were means with $\mathrm{n}=7$ per treatment.

vitamin $\mathrm{B}_{6}$ status. In chicks, the lowering of blood aspartate aminotransferase and alanine aminotransferase activities was found to be specific for vitamin $B_{6}$ deprivation when the deficiencies of vitamin $\mathrm{B}_{6}$, riboflavin, pantothenic acid, thiamine, niacin, and biotin were tested (Cheney et al., 1965) and similar results were also observed by Yen et al. (1976) and Oloyo (2001). In our study, pyridoxine status influenced aspartate aminotransferase $(p<0.0001)$ but not alanine aminotransferase $(\mathrm{p}=0.5219$, Table 3$)$. The aspartate aminotransferase activity showed a quadratic

Table 3. Effects of pyridoxine on transaminase and homocysteine in plasma of White Pekin ducks at 28 days of age ${ }^{1}$

\begin{tabular}{|c|c|c|c|}
\hline Items & $\begin{array}{c}\text { Aspartate } \\
\text { aminotransferas } \\
(\mathrm{U} / \mathrm{L})\end{array}$ & $\begin{array}{c}\text { Alanine } \\
\text { e aminotransferase } \\
(\mathrm{U} / \mathrm{L})\end{array}$ & $\begin{array}{l}\text { Homocysteine } \\
\qquad(\mu \mathrm{mol} / \mathrm{L})\end{array}$ \\
\hline \multicolumn{4}{|c|}{$\begin{array}{l}\text { Supplemental pyridoxine } \\
(\mathrm{mg} / \mathrm{kg})\end{array}$} \\
\hline 0.00 & 17.9 & 12.3 & 26.5 \\
\hline 0.66 & 30.5 & 15.2 & 11.7 \\
\hline 1.32 & 32.4 & 14.8 & 13.2 \\
\hline 1.98 & 35.1 & 13.0 & 11.8 \\
\hline 2.64 & 31.1 & 14.8 & 10.6 \\
\hline 3.30 & 27.8 & 15.7 & 9.5 \\
\hline 3.96 & 27.4 & 13.3 & 9.9 \\
\hline Pooled SEM & 0.87 & 0.50 & 0.59 \\
\hline \multicolumn{4}{|l|}{ Probability } \\
\hline Pyridoxine & $<0.0001$ & 0.5219 & $<0.0001$ \\
\hline $\begin{array}{l}\text { Pyridoxine } \\
\text { linear }\end{array}$ & 0.5061 & 0.6022 & 0.0590 \\
\hline $\begin{array}{c}\text { Pyridoxine } \\
\text { quadratic }\end{array}$ & 0.0385 & 0.5522 & 0.0538 \\
\hline
\end{tabular}

SEM, standard error of the mean.

${ }^{1}$ Results were means with $\mathrm{n}=7$ per treatment. 
Table 4. Supplemental pyridoxine requirements of White Pekin ducklings from hatch to 28 days of age based on the quadratic regression analysis

\begin{tabular}{lcccc}
\hline Response criterion & Maximum response & Requirement $^{1}(\mathrm{mg} / \mathrm{kg})$ & Probability & $\mathrm{R}^{2}$ \\
\hline Feed/gain $(\mathrm{g} / \mathrm{g})$ & 2.07 & 2.44 & 0.0114 & 0.8933 \\
Aspartate aminotransferase $(\mathrm{U} / \mathrm{L})$ & 34.0 & 2.08 & 0.0385 & 0.8038 \\
Homocysteine $(\mu \mathrm{mol} / \mathrm{L})$ & 8.9 & 2.72 & 0.0538 & 0.7680 \\
\hline
\end{tabular}

${ }^{1}$ It was estimated as $95 \%$ of supplemental pyridoxine level at maximum response.

response $(\mathrm{p}=0.0385)$ to increasing supplemental pyridoxine levels and the ducks fed vitamin $\mathrm{B}_{6}$-deficient basal diets had the lowest aspartate aminotransferase activity compared with other birds fed pyridoxinesupplemented diets. This was identical with the observed growth response data which showed that the ducks fed basal diets had the lowest weight gain compared with other birds (Table 2). Therefore, our results confirmed the sensitivity of transaminase to pyridoxine deficiency in ducks.

On the other hand, pyridoxine plays a role in the degradation of homocysteine as a coenzyme in the form of PLP and the importance of this vitamin for lowering plasma homocysteine is widely recognized as plasma homocysteine is considered to be a risk factor for cardiovascular disease. Pyridoxine deficiency can lead to the significant elevations of plasma homocysteine in rats or pigs (Smolin et al., 1983; Martinez et al., 2000; Lima et al., 2006; Zhang et al., 2009) and thus plasma homocysteine may be another new indicator for vitamin $\mathrm{B}_{6}$ status, which was also confirmed by our results. In our study, the ducks fed basal diets had the highest level of plasma homocysteine among all ducks and it was reduced linearly $(\mathrm{p}=0.0590)$ or quadratically $(\mathrm{p}=$ 0.0538 ) when pyridoxine was supplemented to basal diets (Table 3). Recently, the reason in which homocysteine increased during prydoxine deficiency was investigated in pigs by Zhang et al. (2009) who found that there was a decrease in PLP-dependent enzymes (cystathionine $\beta$ synthase and cystathionine $\gamma$-lyase) in the transsulfuration pathway for degradation of homocyteine when this vitamin was deficient.

In the present study, the feed/gain and aspartate aminotransferase showed a quadratic response to increasing supplemental pyridoxine levels $(p=0.0114$ and $p=0.0385)$ and homocysteine showed quadratic trend as this vitamin level increased $(\mathrm{p}=0.0538)$. Therefore, the quadratic regressions were used to estimate the supplemental pyridoxine requirements of ducks (Table 4). According to this regression, the maximum responses for feed/gain, plasma aspartate aminotransferase, and plasma homocysteine were $2.07,34.0 \mathrm{U} / \mathrm{L}$, and $8.9 \mu \mathrm{mol} / \mathrm{L}$, respectively, and the corresponding supplemental requirements of this vitamin for these criteria were 2.44, 2.08, and 2.72, respectively (Table 4). The estimated requirements for feed/gain and plasma aspartate aminotransferase were more accurate than the value for plasma homocysteine because they had a much lower pvalue and higher $\mathrm{R}^{2}$ for regression compared to plasma homocysteine (Table 4). Furthermore, the estimated responses and requirements for feed/gain and plasma aspartate aminotransferase were close to the observed response data indicating that feed/gain and plasma aspartate aminotransferase were optimized when supplemental pyridoxine levels were 2.64 and $1.98 \mathrm{mg} / \mathrm{kg}$, respectively (Tables 2 and 3), but the observed data was not for the estimated response and requirement for plasma homocysteine. When the pyridoxine concentration of the basal diet $(1.93 \mathrm{mg} / \mathrm{kg})$ was included, the total pyridoxine requirements of Pekin ducks were predicted to $4.37 \mathrm{mg} / \mathrm{kg}$ for feed/gain and 4.01 for plasma aspartate aminotransferase and these values were much higher than the NRC recommendation $(2.5 \mathrm{mg} / \mathrm{kg})$ for White Pekin ducks. However, it should be acknowledged that NRC recommendation for this vitamin was available pyridoxine requirements because this recommendation was obtained from duck trials in which vitamin $\mathrm{B}_{6}$-free purified diets and crystal pyridoxine hydrochlorate salt were used (Hegsted and Rao, 1945).

In conclusion, pyridoxine deficiency can cause growth depression and deficiency of this vitamin can be indicated by decreasing aspartate aminotransferase activity and increasing homocysteine in plasma. The supplemental and total pyridoxine requirements of Pekin ducks from hatch to 28 days of age were 2.44 and $4.37 \mathrm{mg} / \mathrm{kg}$ for feed/gain and 2.08 and $4.01 \mathrm{mg} / \mathrm{kg}$ for plasma aspartate aminotransferase, respectively.

\section{ACKNOWLEDGMENTS}

The work was supported by Beijing Municipal Natural Science Foundation (6133034) and Basic Science Research Program in National Institutes of China (2012cj-4).

\section{REFERENCES}

Cheney, M. C., D. M. Curry, and G. H. Beaton. 1965. Blood transaminase activities in vitamin $\mathrm{B}_{6}$ deficiency: Specificity and sensitivity. Can J. Physiol. Pharmacol. 43:579-589.

Gilfix, B. M., D. W. Blank, and D. S. Rosenblatt. 1997. Novel reducetant for determination of total plasma homocysteine. Clin. Chem. 43:687-688. 
Hegsted, D. M. and M. N. Rao. 1945. Nutritional studies with the duck: II. Pridoxine deficiency. J. Nutr. 30:367-374.

Lima, C. P., S. R. Davis, A. D. Mackey, J. B. Scheer, J. Williamson, and J. F. Gregory III. 2006. Vitamin B-6 deficiency suppresses the hepatic transsulfuration pathway but increases glutathione concentration in rats fed AIN-76A or AIN-93G diets. J. Nutr. 136:2141-2147.

Martinez, M., G. J. Cuskelly, J. Williamson, J. P. Toth, and J. F. Gregory. 2000. Vitamin B-6 deficiency in rats reduces hepatic serine hydroxymethyltransferase and cystathionine $\beta$-synthase activities and rates of in vivo protein turnover, homocysteine remethylation and transsulfuration. J. Nutr. 130:1115-1123.

Miles, E. W. and J. P. Kraus. 2004. Cystathionine $\beta$-synthase: Structure, function, regulation, and location of homocystinuriacausing mutations. J. Biol. Chem. 279:29871-29874.

Ministry of Health of China. 2010. Determination of vitamin $B_{6}$ in foods for infants and young children, milk and milk products. Standards Press of China, Beijing, China.

National Research Council. 1994. Nutrient Requirements of Poultry. 9th Ed. National Academy Press, Washington, DC, USA.

Oloyo, R. A. 2001. Pyridoxine requirement of broilers on fed guinea corn-palm kernel meal based diet. Pertanika J. Trop. Agric. Sci. 24:159-164.

Pfeiffer, C. M., D. L. Huff, and E. W. Gunter. 1999. Rapid and accurate HPLC assay for plasma total homocysteine and cysteine in a clinical laboratory. Clin. Chem. 45:290-292.
Reynolds, R. D. 1988. Bioavailability of vitamin B-6 from plant foods. Am. J. Clin. Nutr. 48:863-867.

SAS Institute. 2003. SAS User's Guide: Statistics. Version 9.0. SAS Institute, Inc., Cary, NC, USA.

Selhub, J. 1999. Homocysteine metabolism. Annu. Rev. Nutr. 19: 217-246.

Smolin, L. A., T. D. Crenshaw, D. Kurtycz, and N. J. Benevenga. 1983. Homocyst(e)ine accumulation in pigs fed diets deficient in Vitamin B-6: Relationship to atherosclerosis. J. Nutr. 113: 2022-2033.

Trumbo, P. R., J. F. Gregory III, and D. B. Sartain. 1988. Incomplete utilization of pyridoxine- $\beta$-glucoside as vitamin B6 in the rat. J. Nutr. 118: 170-175.

Ubbink, J. B., W. J. Hayward Vermaak, and S. Bissbort, 1991. Rapid high-performance liquid chromatogramphic assay for total homocysteine levels in human serum. J. Chromatogr. B. Biomed. Sci. Appl. 565:441-446.

Yen, J. T., A. H. Jensen, and D. H. Baker. 1976. Assessment of the concentration of biologically available vitamin B-6 in corn and soybean meal. J. Anim. Sci. 42:866-870.

Zhang, Z., E. Kebreab, M. Jing, J. C. Rodriguez-Lecompte, R. Kuehn, M. Flintoft, and J. D. House. 2009. Impairments in pyridoxine-dependent sulphur amino acid metabolism are highly sensitive to the degree of vitamin $\mathrm{B}_{6}$ deficiency and repletion in the pig. Animal 3:826-837. 